\title{
Decrease in breast cancer incidence following a rapid fall in use of hormone replacement therapy in Australia
}

\author{
Karen Canfell, Emily Banks, Aye M Moa and Valerie Beral
}

F irst results from the Women's Health Initiative randomised controlled trial comparing combined hormone replacement therapy (HRT) with placebo, published in July 2002, showed a significant increase in the risk of breast cancer, coronary heart disease, venous thromboembolism and stroke among women using HRT. ${ }^{1}$ The investigators concluded that the overall adverse effects of HRT use outweighed the benefits. This publication, along with subsequent prescribing advice from drug regulatory authorities, led to a rapid drop in the prevalence of HRT use. In the United States, an $11 \%$ reduction in breast cancer incidence from 2001 to 2004 was reported in women aged 50 years or older, and this was attributed largely to the decline in use of HRT. ${ }^{2}$ Similar trends have been reported by many, but not all, investigators in the US and other countries. ${ }^{3-15}$

Here, we examine whether declining use of HRT in Australia after 2001 was followed by a fall in the incidence of invasive breast cancer among women aged 50 years or older (the age group comprising the majority of women who use HRT), but not among younger women.

\section{METHODS}

Our analyses covered the years 1996-2003 because of an availability of consistently recorded information on HRT prescriptions and cancer incidence in Australia, and because substantial changes in HRT use and breast cancer incidence were noted in the US during this period. ${ }^{2-8}$

We used data from the Pharmaceutical Benefits Scheme and Repatriation Pharmaceutical Benefits Scheme databases (together termed the "PBS database" here) to describe national trends in dispensed HRT prescriptions (termed "prescriptions" here). ${ }^{16}$ Although the PBS database includes information on subsidised prescriptions for medicines above the copayment threshold for general patients, this was not consistently recorded over the period of interest because the relative pricing of the various preparations varied in a complex way. In contrast, HRT prescriptions were consistently recorded on the database for concession cardholders

\section{ABSTRACT}

Objective: To determine if the recent rapid fall in use of hormone replacement therapy (HRT) in Australia has been followed by a reduction in breast cancer incidence among women aged 50 years or older, but not among younger women.

Design and setting: Analysis of trends in annual prescribing of HRT, using Pharmaceutical Benefits Scheme data, and in annual age-standardised breast cancer incidence rates in Australian women for the period 1996-2003.

Results: In Australia, prescribing of HRT increased from 1996 to 2001, but dropped by 40\% from 2001 to 2003. Age-standardised breast cancer incidence rates in women aged $\geqslant 50$ years also increased to 2001 but declined thereafter. The incidence rates in this age group were lower by $6.7 \%(95 \% \mathrm{Cl}, 3.9 \%-9.3 \%$; $P<0.001)$ in 2003 compared with 2001, equivalent to $600(95 \% \mathrm{Cl}, 350-830)$ fewer breast cancers (out of about 9000 incident breast cancers annually for women this age). There was no significant change in breast cancer incidence for women aged $<50$ years.

Conclusions: While other factors may have contributed to a recent reduction in breast cancer incidence among Australian women aged $\geqslant 50$ years, the available evidence suggests that much of the decrease is due to the recent fall in use of HRT. This is consistent with other evidence that the HRT-associated increase in risk of breast cancer is reversible after ceasing use of HRT.

MJA 2008; 188: 641-644

and patients captured under the Medicare Safety Net scheme (collectively termed "concession cardholders" here) during the study period, ${ }^{17}$ and so we restricted our analyses of prescribing trends to this group. Prescriptions defined as HRT were oral or transdermal oestrogen-only HRT, or combined oestrogenprogestogen HRT preparations (tibolone prescriptions are not subsidised and so could not be included).

Changes in HRT use among concession cardholders may not necessarily be representative of all women in Australia, and the size and composition of the concession cardholders group may have changed over time, so trends in prescribing among this group were confirmed by comparison with trends in HRT use from other data sources. These secondary sources were the annual Australian statistics on medicines reports, which use a combination of PBS data and survey data from a sample of community pharmacies; ${ }^{18}$ and the National Health Survey, which provides self-reported information on current HRT use in samples of Australian women at various times. ${ }^{19,20}$

We used breast cancer incidence data from the Australian Institute of Health and Welfare, which compiles data from state registries on cancers diagnosed in Australia each year. ${ }^{21}$ We used code C50 (invasive breast cancer) of the International classification of diseases, 10th revision. ${ }^{22}$

Annual breast cancer incidence rates were age-standardised by direct standardisation using the 2001 Australian Standard Population. ${ }^{23}$ Since the average age of Australian women is increasing every year, age standardisation provides estimates that can be compared directly from one year to another, without the confounding effect of the ageing of the population.

Trends in breast cancer incidence were analysed for women of all ages, women $<50$ years old, and women $\geqslant 50$ years old. For each age group, we compared incidence rates in 2001 (before publication of the Women's Health Initiative trial results) with rates in 2003 (the most recent year for which national incidence data were available). We modelled the age-specific rates using Poisson regression, with the model including age as a factor, and indicator variables for the year $(2003 \mathrm{v} 2001)$ and for the year and broad age groups ( $20-49$ years $v \geqslant 50$ years). The logarithm of the population size was included as an offset. 


\section{RESULTS}

The number of HRT prescriptions among concession cardholders increased from 2089834 in 1996 to 3070299 in 2001, and then dropped by $40 \%$ to 1854060 in 2003 (Box 1). Declines of similar magnitude from 2001 to 2003 were observed in prescriptions for oestrogen-only preparations (39\% decline), combined oestrogen-progestogen preparations ( $41 \%$ decline), and if prescriptions captured under the Medicare Safety Net scheme were excluded (40\% decline).

Data from the Australian statistics on medicines $^{18}$ reports showed a decline in combined HRT use of $47 \%$ from 2001 to 2003 (comparable data on oestrogen-only HRT are not available from this source). Data from the National Health Survey also showed a substantial reduction in use of HRT $(21 \%$ of women aged $\geqslant 50$ years reported being current users of HRT in 2001 , and $11 \%$ of women aged $\geqslant 45$ years reported current use in 2004-05). ${ }^{19,20}$ Although not strictly comparable, these figures are broadly consistent with the reduction in HRT prescriptions observed among concession cardholders.

The age-standardised incidence of breast cancer per 100000 Australian women across all ages was 109.1 in 1996, rising gradually to 117.2 in 2001 and then decreasing to 111.8 in 2003. Among women aged $<50$ years, incidence rates remained stable over this period, with age-standardised incidence rates per 100000 women of 33.8, 33.9 and 34.6 in 1996, 2001 and 2003, respectively (Box 2). For these women, rates in 2003 had non-significantly increased by $1.7 \%$ (95\% CI, $-3.4 \%$ to $7.1 \%$ ) compared with $2001(P=0.5)$.

However, among women aged $\geqslant 50$ years, the age-standardised incidence of breast cancer per 100000 women increased from 281.1 in 1996 to 308.3 in 2001, and then decreased to 287.4 in 2003 (Box 2). From 2001 to 2003, age-standardised incidence rates in this age group fell by $6.7 \%$ (95\% CI, 3.9\%-9.3\%; $P<0.001$ ), equivalent to 600 fewer breast cancers (95\% CI, 350830 ) in women aged $\geqslant 50$ years in 2003 compared with 2001.

\section{DISCUSSION}

We found that the substantial reduction in HRT prescriptions that occurred in Australia after 2001 was accompanied by a statistically significant fall in breast cancer incidence among women aged $\geqslant 50$ years, but
1 Hormone replacement therapy (HRT) prescriptions among concession cardholders in Australia, 1996-2003

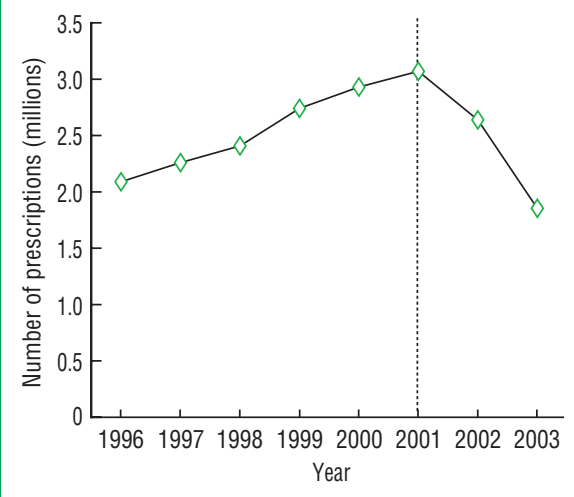

Vertical dotted line indicates commencement of the period over which HRT prescriptions were expected to decline.

\section{Age-standardised incidence of invasive breast cancer in women in Australia, 1996-2003}

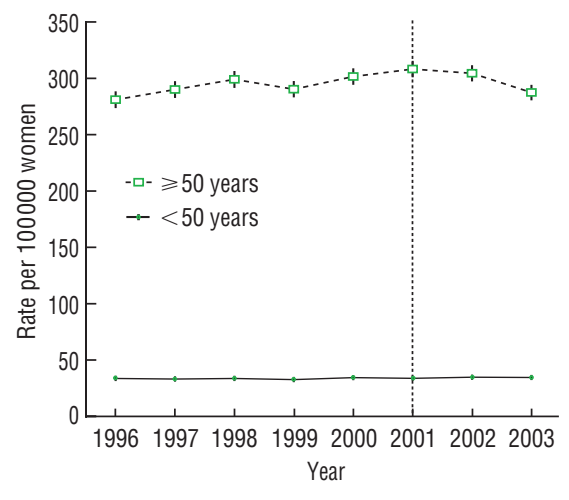

Vertical bars represent $95 \% \mathrm{Cls}$ (confidence intervals are very small for women aged $<50$ years). Vertical dotted line indicates commencement of the period over which there was a hypothesised decrease in breast cancer incidence in women aged $\geqslant 50$ years but not in women aged $<50$ years.

not by any significant change in incidence among younger women. Our results show a $40 \%$ drop in PBS prescriptions for HRT from 2001 to 2003 and, over the same period, a significant $6.7 \%$ decline in the incidence of invasive breast cancer among Australian women aged $\geqslant 50$ years, who comprise the majority of HRT users.

Our analyses were designed to replicate, in an Australian setting, analyses carried out in the US that found a decline in breast cancer incidence after 2001 among women aged $\geqslant 50$ years (which was attributed mainly to a drop in HRT use), but not among younger women. ${ }^{2,3,6-8}$ Our results are in broad agreement with those reported from the US.

We compared HRT prescribing trends among concession cardholders in Australia with estimates of changes in HRT use over time using two other data sources. While the National Health Survey data are not strictly comparable, as they cover a longer time period and the age groups studied varied over time, all three data sources consistently showed a rapid and substantial drop of similar magnitude in the use of HRT after 2001.

The fact that a rapid drop in HRT use is followed by a reduction in breast cancer incidence does not necessarily establish a causal connection between the two. Other factors can contribute to short-term changes in national breast cancer incidence rates, and by far the most pertinent of these for women aged $\geqslant 50$ years is breast cancer screening. ${ }^{24,25}$ The biennial age-standardised breast cancer screening participation rates for Australian women aged 50-69 years were $51.4 \%$ (95\% CI, 51.3\%-51.6\%) in $1996-1997$; $56.9 \%$ (95\% CI, 56.8\%$57.0 \%)$ in 2000-2001 and 56.1\% (95\% CI, $55.9 \%-56.2 \%$ ) in $2002-2003 .{ }^{26}$ Although annual rates are not published, the slight reduction in rates between 2000-2001 and $2002-2003$ (from $56.9 \%$ to $56.1 \%$ ) is too small to account for the $6.7 \%$ decline in breast cancer incidence that we found in women aged $\geqslant 50$ years from 2001 to 2003 .

Changes in screening patterns in the US have also been too small to account for observed decreases in breast cancer incidence. $^{2,3,7}$ The best way to rule out any potential contribution of screening to breast cancer trends is to examine such trends within a screened population. One study in the US did so, and found that among women attending for screening there had been a recent fall in breast cancer incidence corresponding to the decrease in HRT use. $^{6,27}$

In other countries where HRT use has decreased recently, screening patterns have sometimes changed at the same time, making it impossible to separate out the effects of changes in screening and in HRT use. For example, in England, two-view mammography for all screens was introduced from 2002, substantially increasing the detection of breast cancers ${ }^{24}$ and largely obscuring any effect of changes in HRT use. In Norway, the national breast screening program began in 1996, but only achieved complete geographic coverage in $2004 .{ }^{28}$ It is difficult to interpret the relevance of a report stating 
that breast cancer incidence rates in four Norwegian counties did not change between 2001 and 2005, ${ }^{13}$ particularly since the population is small and the incidence rates presented appear to differ from those published by the Cancer Registry of Norway. ${ }^{28}$

In New Zealand, HRT prescriptions fell by a third from 2001 to 2003 and breast cancer incidence rates fell by $6 \%$ over the same period. ${ }^{11,29}$ A national breast cancer screening program was established in NZ in $1998,{ }^{30}$ and the extent to which changes in screening may have contributed to the decline is unknown.

In Canada, a slight decline in breast cancer incidence has been seen since 1999, mainly in women aged over 75 years. ${ }^{9}$ Data from one cancer registry in Germany show a significant decline in breast cancer incidence between 2001 and 2005 in women aged 5069 years, but not at younger ages. ${ }^{10}$ However, these studies provided no information on screening patterns.

In other studies, the prevalence of HRT use was too low and/or statistical power was too limited to detect a difference in breast cancer incidence. HRT use has been much less common in the Netherlands and in northern Italy than in the US or Australia. Although HRT use in these countries fell after 2001, the reduction in use was far too small to lead to a detectable decrease in breast cancer incidence. ${ }^{14,15,31,32}$

It has been suggested that the observed recent decline in breast cancer incidence in Australia may have been due to increased use of drugs such as tamoxifen and raloxifene. However, PBS data show that prescribing of tamoxifen among concession cardholders remained relatively constant between 2001 and 2003. ${ }^{16}$ Prescriptions for raloxifene in 2001 were 13 times less common than those for HRT, ${ }^{16}$ and so it is unlikely to have had a substantial effect on national breast cancer incidence rates.

Results from randomised trials and observational studies have consistently found that combined HRT causes a greater increase in breast cancer incidence than oestrogen-only preparations. In a recently published metaanalysis by the United Kingdom's drug regulatory authority, the relative risks of breast cancer were greater for combined HRT than oestrogen-only HRT in 20 of the 21 studies reviewed (including the Women's Health Initiative trial). ${ }^{33}$

The evidence on breast cancer risk associated with use of tibolone (a synthetic nonhormonal HRT) was also reviewed by the UK drug regulatory authority, and although some, but not all studies, reported an increased risk of breast cancer, in no study was the risk as great as that found for combined HRT. ${ }^{34}$ As tibolone is not subsidised in Australia, there are no relevant PBS prescription data. The limited information available through the Australian statistics on medicines reports suggests that tibolone use increased until 2003 but declined thereafter. ${ }^{18}$ As use of tibolone is associated with a smaller effect on breast cancer than combined HRT, the lack of PBS prescribing data for tibolone would not materially affect the interpretation of our findings.

The increased risk of breast cancer associated with HRT use is greatest in current users, and the excess risk falls after use ceases. Analysis of worldwide evidence, published in 1997 and including data from 51 studies, showed that the risk of breast cancer in past users of HRT had returned to that found in never-users within 5 years of stopping. ${ }^{35}$ Recent data from a large UK study showed that, compared with neverusers, the HRT-associated relative risk for breast cancer was 1.66 (95\% CI, 1.58-1.75) in current users but fell to 1.14 (95\% CI, 1.01-1.28) within a year after use had stopped. ${ }^{36}$ The decline in breast cancer incidence rates seen soon after a substantial drop in the prevalence of HRT use in Australia is thus consistent with other evidence showing that the HRT-associated increase in breast cancer risk is rapidly reversible after use ceases.

HRT use tends to increase the risk of oestrogen receptor (ER)-positive tumours, and the fall in breast cancer incidence in the US after 2001 was largely confined to ERpositive tumours. ${ }^{2,6}$ Unfortunately, routinely collected breast cancer data in Australia do not include ER status, so we were unable to describe trends over time in the rates of ERpositive and ER-negative tumours.

The $6.7 \%$ fall in age-standardised incidence of breast cancer in Australian women aged $\geqslant 50$ years in 2003 compared with 2001 is equivalent to 600 (95\% CI, 350830) fewer breast cancers among women in this age group (out of a total of about 9000 incident breast cancers at this age annually). Based on patterns of HRT use and published data on HRT-associated risks, others have estimated that 1066 breast cancers in Australian women in 2001 were attributable to use of HRT. ${ }^{37}$ If this estimate is correct, and if the $40 \%$ decline in prescribing of HRT in concession cardholders from 2001 to 2003 is representative of the pattern of use in all Australian women, and if this also led to a
$40 \%$ reduction in HRT-attributable breast cancer cases, an estimated 430 fewer breast cancers would be expected in 2003 compared with 2001. Although a number of assumptions underlie these calculations, and other unmeasured factors may also be contributing, the correspondence between the decline we observed and such independently derived estimates suggests that much of the decrease in breast cancer incidence in older women in Australia since 2001 is due to the rapid fall in HRT use.

\section{ACKNOWLEDGEMENTS}

We thank Associate Professor Dianne O'Connell and Dr Mark Clements for statistical support. We also thank Professor Bruce Armstrong for helpful review of a draft of the manuscript. Yoon Jung Kang, Research Assistant at The Cancer Council NSW, assisted with data checking. Aye Moa participated in this research as a volunteer for The Cancer Council NSW.

\section{COMPETING INTERESTS}

None identified.

\section{AUTHOR DETAILS}

Karen Canfell, DPhil, Sydney Rotary Research Fellow ${ }^{1}$

Emily Banks, MB BS(Hons), PhD, FAFPHM, NHMRC Senior Research Fellow and Scientific Director, The 45 and Up Study ${ }^{2}$

Aye M Moa, MPH, Research Assistant ${ }^{1}$ Valerie Beral, FRS, Professor and Director ${ }^{3}$

1 Cancer Epidemiology Research Unit, The Cancer Council NSW, Sydney, NSW.

2 National Centre for Epidemiology and Population Health, Australian National University, Canberra, ACT.

3 Cancer Epidemiology Unit, University of Oxford, Oxford, UK.

\section{Correspondence: karenc@nswcc.org.au}

\section{REFERENCES}

1 Rossouw JE, Anderson GL, Prentice RL, et al; Writing Group for the Women's Health Initiative Investigators. Risks and benefits of estrogen plus progestin in healthy postmenopausal women: principal results from the Women's Health Initiative randomized controlled trial. JAMA 2002; 288: 321-333.

2 Ravdin PM, Cronin KA, Howlader N, et al. The decrease in breast-cancer incidence in 2003 in the United States. N Engl J Med 2007; 356: 1670-1674

3 Clarke CA, Glaser SL, Uratsu CS, et al. Recent declines in hormone therapy utilization and breast cancer incidence: clinical and population-based evidence. J Clin Oncol 2006; 24: e49-e50.

4 Clarke CA, Glaser SL. Declines in breast cancer after the WHI: apparent impact of hormone therapy. Cancer Causes Control 2007; 18: 847852. 
5 Robbins AS, Clarke CA. A decline in breastcancer incidence. N Engl J Med 2007; 357: 511512.

6 Kerlikowske K, Miglioretti DL, Buist DS, et al; National Cancer Institute-Sponsored Breast Cancer Surveillance Consortium. Declines in invasive breast cancer and use of postmenopausal hormone therapy in a screening mammography population. J Natl Cancer Inst 2007; 99: 1335-1339.

7 Glass AG, Lacey JV Jr, Carreon JD, Hoover RN. Breast cancer incidence, 1980-2006: combined roles of menopausal hormone therapy, screening mammography, and estrogen receptor status. J Natl Cancer Inst 2007; 99: 1152-1161.

8 Jemal A, Ward E, Thun MJ. Recent trends in breast cancer incidence rates by age and tumor characteristics among US women. Breast Cancer Res 2007; 9: R28.

9 Kliewer EV, Demers AA, Nugent ZJ. A decline in breast-cancer incidence. N Engl J Med 2007; 357: 509-510.

10 Katalinic A, Rawal R. Decline in breast cancer incidence after decrease in utilisation of hormone replacement therapy. Breast Cancer Res Treat 2008; 107: 427-430.

11 Johnston M. Breast cancer drop linked to fall in use of HRT. New Zealand Herald 2006; 20 Dec. http://www.nzherald.co.nz/section/story. cfm?c_id=204\&objectid=10416198 (accessed Dec 2007).

12 Keegan TH, Chang ET, John EM, et al. Recent changes in breast cancer incidence and risk factor prevalence in San Francisco Bay area and California women: 1988 to 2004. Breast Cancer Res 2007; 9: R62.

13 Zahl PH, Maehlen J. A decline in breast-cancer incidence [letter]. N Engl J Med 2007; 357: 510511.

14 Ponti A, Rosso S, Zanetti R, et al. Re: Breast cancer incidence, 1980-2006: combined roles of menopausal hormone therapy, screening mammography, and estrogen receptor status [letter]. J Natl Cancer Inst 2007; 99: 1817-1818.

15 Soerjomataram I, Coebergh JW, Louwman $M W$, et al. Does the decrease in hormone replacement therapy also affect breast cancer risk in the Netherlands [letter]? J Clin Oncol 2007; 25: 5038-5039.
16 Medicare Australia. PBS Statistics [website]. http://www.medicareaustralia.gov.au/providers/health_statistics/statistical_reporting/ pbs.htm (accessed Dec 2007).

17 Australian Government Department of Health and Ageing. Schedule of pharmaceutical benefits for approved pharmacists and medical practitioners [1996-2003]. Canberra: Department of Health and Ageing, 2003.

18 Australian Government Department of Health and Ageing. Australian statistics on medicines [1997-2005]. Canberra: Department of Health and Ageing, 2007. http://www.health.gov.au/ internet/main/publishing.nsf/Content/healthpbs-general-pubs-asm.htm (accessed Dec 2007).

19 Australian Bureau of Statistics. National Health Survey: summary of results, Australia, 2001. Canberra: ABS, 2002. (ABS Cat. No. 4364.0.)

20 Australian Bureau of Statistics. National Health Survey: summary of results, Australia, 2004-05. Canberra: ABS, 2006. (ABS Cat. No. 4364.0.)

21 Australian Institute of Health and Welfare. Australian cancer incidence and mortality (ACIM) books. Canberra: AlHW, 2007.

22 World Health Organization. International statistical classification of diseases and related health problems, 10th revision. http:// www.who.int/classifications/apps/icd/ icd10online/ (accessed Dec 2007).

23 Australian Institute of Health and Welfare, Australasian Association of Cancer Registries. Cancer in Australia: an overview, 2006. Canberra: AlHW, 2007. (AlHW Cat. No. CAN 32.)

24 Advisory Committee on Breast Cancer Screening. Screening for breast cancer in England: past and future. NHSBSP Publication No 61. Sheffield: NHS Cancer Screening Programmes, 2006.

25 International Agency for Research on Cancer. IARC handbooks of cancer prevention Vol. 7. Breast cancer screening. Lyon: IARC Press, 2002.

26 Australian Institute of Health and Welfare. BreastScreen Australia monitoring report 20032004. Canberra: AlHW, 2007. (AlHW Cat. No. CAN 31.)

27 Kerlikowske K, Buist DS, Walker R. Response: $R e$ : declines in invasive breast cancer and use of postmenopausal hormone therapy in a screening mammography population [letter]. J Natl Cancer Inst 2007; 99: 1816-1817.

28 Hofvind S, Sørum R, Thoresen S. Incidence and tumor characteristics of breast cancer diagnosed before and after implementation of a population-based screening-program. Acta Oncol 2007; Sep 12: 1-7.

29 New Zealand Health Information Service. Cancer: new registrations and deaths [2001-2003]. Wellington: Ministry of Health, 2007.

30 Richardson A, Graham P, Brown T, et al. Breast cancer detection rates, and standardised detection ratios for prevalence screening in the New Zealand breast cancer screening programme. J Med Screen 2004; 11: 65-69.

31 Clarke CA, Robbins AS. In reply: Does the decrease in hormone replacement therapy also affect breast cancer risk in the Netherlands [letter]? J Clin Oncol 2007; 25: 5039-5040.

32 Robbins AS, Clarke CA. Re: Declines in invasive breast cancer and use of postmenopausal hormone therapy in a screening mammography population [letter]. J Natl Cancer Inst 2007; 99: 1815.

33 Medicines and Healthcare products Regulatory Agency. UK public assessment report. Hormone-replacement therapy: safety update. London: MHRA, 2007.

34 Medicines and Healthcare products Regulatory Agency. UK public assessment report. Tibolone (Livial): benefit-risk evaluation. London: MHRA, 2007.

35 Collaborative Group on Hormonal Factors in Breast Cancer. Breast cancer and hormone replacement therapy: collaborative reanalysis of data from 51 epidemiological studies of 52,705 women with breast cancer and 108,411 women without breast cancer. Lancet 1997; 350: 1047-1059.

36 Beral V; Million Women Study Collaborators. Breast cancer and hormone-replacement therapy in the Million Women Study. Lancet 2003; 362: 419-427.

37 Coombs NJ, Taylor R, Wilcken N, Boyages J. HRT and breast cancer: impact on population risk and incidence. Eur J Cancer 2005; 41: 17751781.

(Received 4 Oct 2007, accepted 12 Dec 2007) 